\title{
PENETRATION OF HYPERVELOCITY PROJECTILES INTO LOW DENSITY MATERIALS
}

\author{
A. FUJIWARA, T. KADONO, and A. NAKAMURA \\ Department of Physics, \\ Kyoto University, \\ Kyoto 606 Japan \\ T. ISHIBASHI ${ }^{+}$, N. FUJI I \\ Department of Earth Science, \\ Kobe University, \\ Kobe 657 Japan
}

\begin{abstract}
Spherical nylon projectiles of $7 \mathrm{~mm}$ diameter and up-to $4 \mathrm{~km} / \mathrm{s}$ velocities were penetrated into three types of targets; aluminum multisheet stacks, foamed polystyrene, and 1-atm air. Penetration depth, recovery rate of the projectiles were determined as a function of projectile velocity and target density, and a new type of dust collector is proposed.
\end{abstract}

\section{INTRODUCTION}

Observation of comet Halley by space probes brought many useful informations on the chemical abundances of the comet. However, determination of the molecular species of the constituent of the cometary particles will be possible after the sample of the cometary dust particles are intactly captured and returned back to the groundbased laboratory. An ISAS/NASA mission plan is proposed to capture the cometary dust particles intactly when the space vehicles fly through the comet coma(Veverka et al.,1989). In the mission, the relative velocity of dust particles and the space vehicle should be made as low as possible to avoid the damage of the dust particles during the capture. However, the planned velocity is still as high as $10-\mathrm{km} / \mathrm{s}$. In order to develop a device to collect dust particles intactly, we are continuing the penetration experiments using projectiles launched by a two-stage light-gas gun at Kyoto University and various kind of low density materials as the catcher materials. Here we present the results of the experiments using (1) multi-sheet stack, (2) foamed polystyrene, and (3) 1-atm air.

+) Now at Japan DEC Computer Co.

A.C. Levasseur-Regourd and H. Hasegawa (eds.), Origin and Evolution of Interplanetary Dust, 281-284.

- 1991 Kluwer Academic Publishers, Printed in Japan. 


\section{ALUMINUM MUL'TI-SHEET STACK}

Spherical nylon projectiles of $7 \mathrm{~mm}$ diameter and $0.213 \mathrm{~g}$ mass were launched into aluminum multi-sheet stacks. A number of aluminum sheets, each $20 \mathrm{~cm} \times 20 \mathrm{~cm}$ were set with some spacings. In this system, the materials are distributed in a localized state, but as we make the sheet thickness thinner and sheet number larger, it gradually tends to the system equivalent with a target of uniformly distributed low density

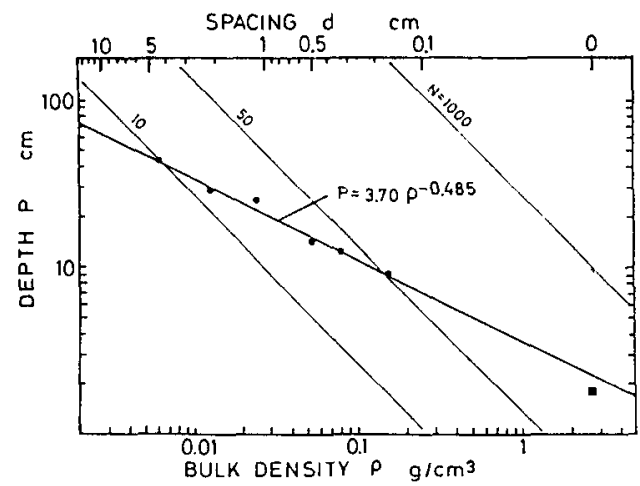

Figure 1. Penetration depth vs bulk density and spacing. velocity $3.85 \mathrm{~km} / \mathrm{s}$. $\mathrm{N}$ is sheet number.

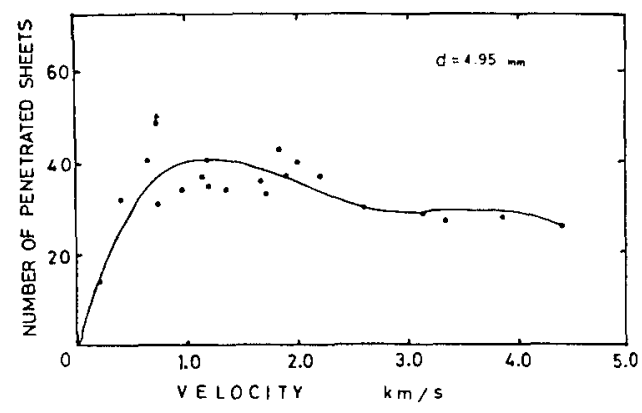

Figure 2. Number of penetrated sheets vs projectile velocity. spacing $4.95 \mathrm{~mm}$.

material. Two series of experiments were performed (Fujiwara and Kadono, 1990); one was carried out at a constant projectile velocity and varying the spacing of the sheets from $0 \mathrm{~cm}$ to $4.4 \mathrm{~cm}$, and another was by varying the projectile velocity and keeping the spacing at a constant value of $5 \mathrm{~mm}$.

RESULTS. The penetration depth vs bulk density or spacing is shown in Fig.1, where the bulk density is defined as the total mass of the aluminum sheets divided by the total volume of the stack including the space between the sheets. The figure shows the penetration depth depends on the -0.485 th power of the bulk density. Fechtig et a1.(1980) report that the depth of the crater formed on the bulk target of normal density depends on the density as the power of -0.5. It is surprising that the target density dependence of the penetration depth on the target density both for the bulk target and the sheet stacks is essentially the same in spite of the apparent difference of the penetration mechanism and the definition of the density. The number of penetrated sheets at a constant spacing vs projectile velocity is shown in Fig.2. It has a broad peak around $1 \mathrm{~km} / \mathrm{s}$. The recovered projectile mass normalized by the original mass as a function of the projectile velocity decreases monotonically to about 0.6 at the velocity of about $3 \mathrm{~km} / \mathrm{s}$. At the velocity higher than $3.3 \mathrm{~km} / \mathrm{s}$, no fragments of the projectile could be found. 


\section{PENETRATION INTO FOAMED POLYSTYRENE}

The same projectiles were launched into foamed polystyrene block targets (Ishibashi et al., 1990). Commercially sold foamed polystyrene has a bulk density of $0.011 \mathrm{~g} / \mathrm{cm}^{3}$ (hereafter called L-type target), and it was uniaxially compressed to get other two kinds of densities; one is 0.033 to $0.040 \mathrm{~g} / \mathrm{cm}^{3}$ (M-type) and another 0.069 to $0.079 \mathrm{~g} / \mathrm{cm}^{3}$ ( $\mathrm{H}$-type).

RESULTS. The penetration depth is found to be expressed by $\rho^{-1.2}$ (where $\rho$ is the target density). In Fig.3, the penetration depth is shown against the impact velocities. As in the case of the aluminum sheet stack, a broad peak is seen as found by Tsou et al.(1986), and it shifts toward higher velocities as the target density becomes lower. The

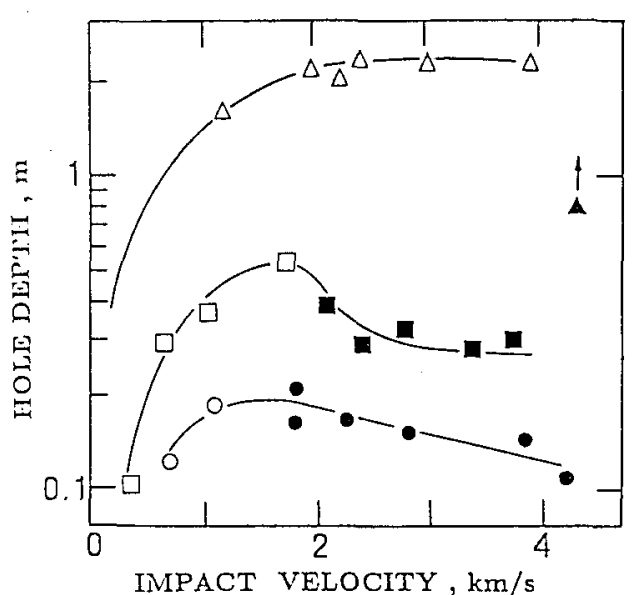

Figure 3. Penetration depth vs impact velocity for foamd polystyrene. target density $\left(\mathrm{g} / \mathrm{cm}^{3}\right)$ : $\triangle 0.011, \square 0.037,00.074$ Filled marks denote the projectile is destroyed.

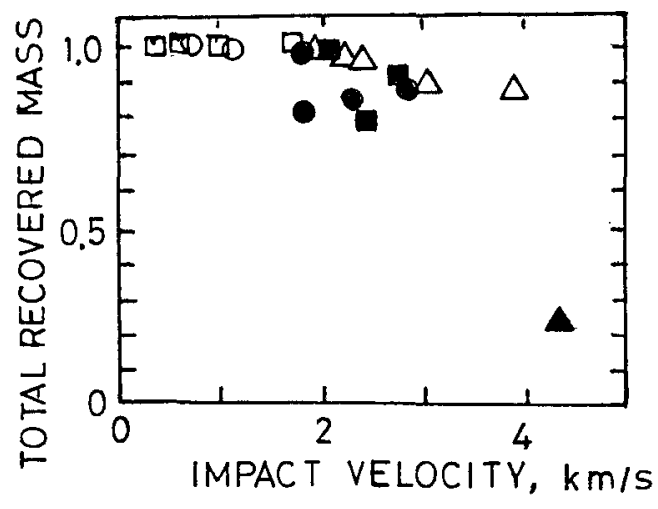

Figure 4. Recovered mass of the projectile in foamed polystyrene. Meaning of the marks is same as

recovery rate is much better for L-type styrofoam(Fig.4). The projectiles were recovered without fragmentation up to $4 \mathrm{~km} / \mathrm{s}$. By extrapolating the velocity at which the fragmentation of the projectile starts as a function of target densities, we found that, if we want to capture the (nylon) projectile of velocity about $10 \mathrm{~km} / \mathrm{s}$ withqut any fragmentation, we must prepare materials of density $0.001 \mathrm{~g} / \mathrm{cm}^{3}$. This density corresponds to that of latm air. Therefore, we further proceeded to make experiments using air targets.

\section{PENETRATION INTO 1-ATM AIR}

The projectiles were launched to test the deceleration efficiency in the open air. The projectiles thrust into the open air after perforating a very thin plastics film which separates the vacuumed chamber and the open air. During the flight in the air, the times when the projectile 
cut successively the very thin grids put at three points along the path were measured. By repeating these measurements with varying initial projectile velocities, we obtained velocity vs flight distance relation. Extrapolating this curve toward higher velocities, it is found that about $6 \mathrm{~m}$ is needed to decelerate the $7 \mathrm{~mm}$ nylon projectile from $10 \mathrm{~km} / \mathrm{s}$ to $4 \mathrm{~km} / \mathrm{s}$.

\section{CONCLUSION}

The system proposed for capturing the dust particles consists of two stages; the first is a gas cell, and the second is a soft material such as foamed polystyrene or something like that. The particle with velocity of $10 \mathrm{~km} / \mathrm{s}$ decelerates to about $4 \mathrm{~km} / \mathrm{s}$ in the first stage, and finally trapped in the second stage. The total length of the system will be in the practical range for the submillimeter dust particles instead of the $7 \mathrm{~mm}$-sized projectiles used in the present experiments.

\section{REFERENCES}

Fechig, H., K. Nagel, and N. Pailer (1980) 'Collisional Processes of Iron and Steel Projectiles on Targets of Different Densities', in I. Halliday and B. A. McIntosh (eds.), Solid Particles in the Solar System, D. Reidel Publishers, Boston, pp. 357-364.

Fujiwara, A., and T. Kadono (1990) 'Penetration of Hypervelocity Projectiles into Aluminum Multisheet Stacks', Jap. J. Appl. Phys. $29,1620-1624$.

Ishibash, T., A. Fujiwara, and N. Fujii (1990), 'Penetration of Hypervelocity Projectiles into Foamed Polystyrene', Jap. J. Appl. Phys. in press.

Tsou, P., D. E. Brownlee, and A. L. Albee (1986), 'Comet Coma Sample Return', ESA spec. Publ. ESA SP-250 3, 237-24.

Veverka, J., Y. Langevin, R. Farquhar, and M. Fulchignoni (1989) 'Spacecraft Exploration of Asteroids: The 1988 Perspective' in R. P. Binzel, T. Gehrels, and M. S. Matthews (eds.), Asteroids II, The University of Arizona Press, Tucson, pp. 970-993. 